\title{
Biosynthesis of the Thiazolylpeptide Antibiotic GE2270
}

\author{
Maria Teresa De Pietro, Alessandra Marazzi, Margherita Sosio, \\ STEFANO DONADIO* ${ }^{*}$ and GIANCARLO LANCINI \\ Biosearch Italia $\mathrm{SpA}$, via R. Lepetit 34, \\ 21040 Gerenzano (VA), Italy
}

(Received for publication June 7, 2001)

\begin{abstract}
The biosynthesis of the antibiotic GE2270 in the producing microorganism Planobispora rosea was investigated by adding labelled amino acid precursors. Efficient incorporation of glycine and serine was observed, leading to specific enrichments of selected positions of the thiazole, oxazoline and pyridine rings. Furthermore, efficient enrichment of the $\mathrm{C}$-, $\mathrm{N}$ - and $\mathrm{O}$ methyl groups was detected. These results indicate that GE2270 is made through a biosynthetic route similar to that determined for other thiazolylpeptides. At the same time, the result point to an efficient route for the conversion of glycine into serine and methyl equivalents in Planobispora rosea.
\end{abstract}

GE2270, a potent antibiotic active against Gram-positive bacteria $^{1)}$, is characterized by a highly modified peptide backbone consisting of six thiazole, one pyridine and one oxazoline rings (Fig. 1). This compound is thus structurally related to other thiazolylpeptide antibiotics (thiostrepton, nosiheptide, etc.) that also consists of a highly modified peptide with several thiazole rings. While all thiazolylpeptides exert their action by inhibiting bacterial protein synthesis, GE2270, together with the closely related molecules amithiamycin ${ }^{2)}$ and GE37468 ${ }^{3)}$, is a potent and selective inhibitor of bacterial elongation factor $\mathrm{Tu}^{4 \sim 6)}$, and thus differs in its molecular target from thiostrepton and related compounds, which bind to the L11 protein in the 23S ribosomal complex ${ }^{7}$. The biosynthesis of thiazolylpeptide antibiotics has been investigated in several instances $^{8 \sim 12}$. These studies have shown that the thiazole rings are labelled by serine, likely after its conversion to cysteine, and that the pyridine ring, also present in the thiostrepton family of antibiotics, derives from the head to head condensation of two serine residues ${ }^{13)}$. By analogy to these molecules, GE2270 is expected to derived from six cysteine residues (to yield thiazole rings $\mathrm{A}$ through $\mathrm{F}$ ), three serine residues (two for the pyridine ring and one for the oxazoline), and one residue each of asparagine, valine, glycine, phenylalanine and proline.
GE2270 is produced by Planobispora rosea, one of the lesser studied genera of actinomycetes ${ }^{14}$. In fact, no other secondary metabolites have been described from this genus. Furthermore, this antibiotic is produced as a complex of several related compounds, differing mostly in the degree of methylation ${ }^{15,16)}$. Two aspects warranted an investigation of GE2270 biosynthesis through the use of labelled precursors: the origin of the $C$-methyls in thiazoles $\mathrm{C}$ and $\mathrm{D}$ (Fig. 1), and a first characterization of antibiotic biosynthesis in a Planobispora sp. These studies are reported herein.

\section{Material and Methods}

The Planobispora rosea strain used in this work was strain GE43782 (from Biosearch Italia strain collection), a GE2270-high-producing derivative obtained by mutagenesis of the parental strain ATCC 53733. The vegetative medium was D-Seed $/ 2(0.5 \%$ peptone, $0.3 \%$ yeast extract, $0.2 \%$ beef extract, $0.2 \%$ soybean meal, $2 \%$ starch, $1 \%$ calcium carbonate, $\mathrm{pH} 7.0$ ), while the production medium was MC-FP ( $2 \%$ starch, $0.25 \%$ peptone, $0.25 \%$ hydrolyzed caseine, $0.3 \%$ yeast extract, $0.2 \%$ beef extract, $0.2 \%$ soybean meal, $2 \%$ starch, $0.11 \%$ calcium carbonate, $\mathrm{pH}$

* Corresponding author: sdonadio@biosearch.it 
Fig. 1. Structure of GE2270.

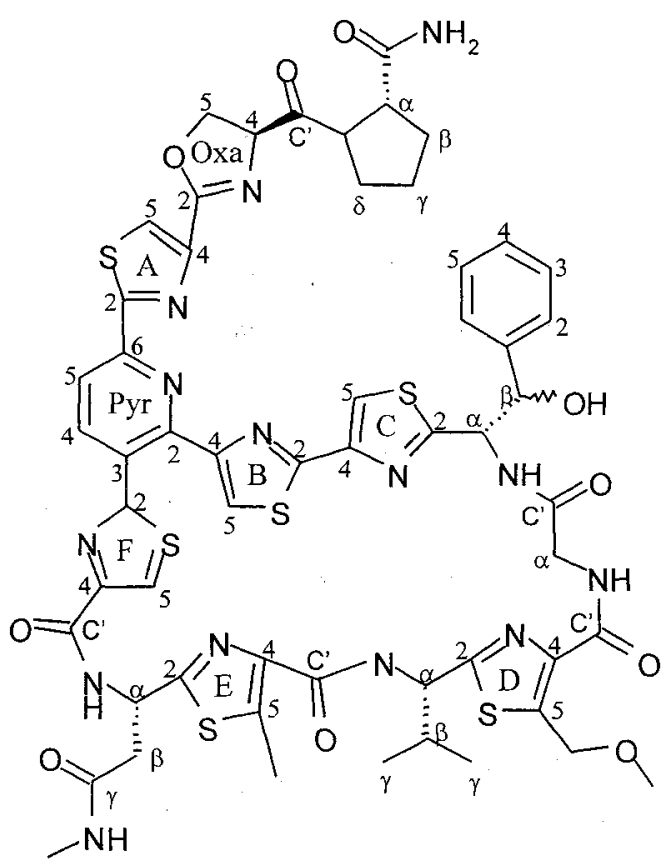

The numbering of rings and atoms is indicated.

7.4) additioned with $50 \mu \mathrm{g} / \mathrm{ml}$ vitamin $\mathrm{B} 12$. Routinely, the strain was grown for 72 hours in vegetative medium before using a $5 \%$ inoculum into production medium. All cultures were grown at $28^{\circ} \mathrm{C}$ with shaking.

All labelled precursors were purchased from Cambridge Isotope Laboratories, except for $\left[2-{ }^{13} \mathrm{C}\right]$ glycine which was from Sigma Aldrich, and were at a ${ }^{13} \mathrm{C}$ purity of $99 \%$. The amount of GE2270 produced under different conditions was evaluated on a Varian HPLC system equipped with a 5 $\mu \mathrm{m} \mathrm{C}_{18}$ column (Beckman). The antibiotic was eluted with a gradient of $2 \mathrm{~g}$ /liter ammonium formate $-\mathrm{CH}_{3} \mathrm{CN}$. Before NMR analysis, the antibiotic was recovered from the pelleted mycelium by extraction twice with 1 vol of $\mathrm{CH}_{3} \mathrm{CN}: \mathrm{H}_{2} \mathrm{O} 7: 3$. The dried extract was then purified by preparative TLC developed with $\mathrm{CH}_{2} \mathrm{Cl}_{2}: \mathrm{CH}_{3} \mathrm{OH}$ 93:7, eluted with $\mathrm{CH}_{2} \mathrm{Cl}_{2}: \mathrm{CH}_{3} \mathrm{OH} \quad 7: 3$ and lyophilized in deuterated DMSO.

Spectra of GE2270 (13 to $21 \mathrm{mg} / \mathrm{ml}$ in DMSO- $d_{6}$ ) were obtained with a Bruker DRX 500 Fourier transform spectrometer under the following conditions: frequency $125.77 \mathrm{MHz}$, acquisition time 0.7 seconds, $32 \mathrm{~K}$ of memory, 11,000 transients, spectral width $26,881 \mathrm{~Hz}$, flip angle $90^{\circ}$, internal reference DMSO- $d_{6} \delta=39.43 \mathrm{ppm}$, temperature $40^{\circ} \mathrm{C}$. Broadband $(1 \mathrm{H})$-decoupling was achieved by inverse gated sequence. The FIDs were processed with $2 \mathrm{~Hz}$ of
Lorentzian line broadening. The distribution of isotopic label was determined by comparing ${ }^{13} \mathrm{C}$ NMR spectra of the enriched and natural abundance compounds recorded and processed under identical experimental conditions. Percent incorporations were determined as ratio $r$, for each peak. The methyl resonance of valine (17.8 ppm) was used as internal reference according to the following formula:

$$
r=\frac{R_{\mathrm{L}}}{R_{\mathrm{N}}} \times \frac{P_{\mathrm{N}}}{P_{\mathrm{L}}}
$$

where $R_{\mathrm{L}}$ is the intensity of the labelled peak, $R_{\mathrm{N}}$ is the intensity of the peak in the natural abundance spectrum, $P_{\mathrm{N}}$ and $P_{\mathrm{L}}$ are the intensities of the valine methyl in natural abundance and labelled spectrum, respectively. Assignments of the various carbons were as in ref. 17, except for those of $\mathrm{C}-4$ and $\mathrm{C}-5$ from thiazole $\mathrm{D}$ (see below).

\section{Results and Discussion}

Under the experimental conditions described in Materials and Methods, the amount of GE2270 produced by the $P$. rosea strain employed in this study varied between 300 and $500 \mu \mathrm{g} / \mathrm{ml}$ after $68 \sim 120$ hours of growth in production medium. Before adding the labelled precursors, GE2270 production was evaluated upon addition of the unlabeled compounds. In 100-ml production medium, the addition of two aliquot of up to $300 \mathrm{mg}$ each of acetate (after 9 and 16 hours of growth), or of up to $30 \mathrm{mg}$ each of DL-serine (after 24 and 48 hours of growth), had little effect on GE2270 titers. However, addition (after 24 and 48 hours) of two 20$\mathrm{mg}$ aliquots of glycine severely reduced GE2270 levels to ca. $100 \mu \mathrm{g} / \mathrm{m} 1$. Nonetheless, these titers were sufficient to recover enough antibiotic for NMR analysis.

A labelling experiment was performed adding $10 \mathrm{mg}$ of $\left[2{ }^{13} \mathrm{C}\right]$-glycine after 24 and 40 hours of growth in the production medium. The total isotopic enrichment, evaluated by MS analysis, was about $50 \%$. The observed specific enrichments have been ascribed to: the $\alpha$-carbon of the glycine residue; to the $\mathrm{C}-4$ positions of the six thiazole rings; to the $\mathrm{C}-5$ positions of thiazole rings $\mathrm{C}, \mathrm{D}$ and $\mathrm{E}$; to the $C$-methyl(ene) groups of thiazoles $\mathrm{D}$ and $\mathrm{E}$; to the $N$ and $O$-methyl groups of thiazole $\mathrm{D}$ and of the Asn residue, respectively; to the $\mathrm{C}-4$ and $\mathrm{C}-5$ carbons of the oxazoline ring; to the $\mathrm{C}-3, \mathrm{C}-4$ and $\mathrm{C}-5$ carbons of the pyridine ring (see Table 1 and Fig. 2). One enrichment was also observed at $150.0 \mathrm{ppm}$, a position corresponding to either $\mathrm{C}-2$ or $\mathrm{C}-6$ of the pyridine ring. By analogy with other thiazolylpetides (see below), this enrichment is likely due to C-6. [It should 
be noted that the signals at 140.7 and $143.3 \mathrm{ppm}$ were originally attributed to $\mathrm{C}-5$ and C-4 positions of thiazole $\mathrm{D}$, respectively. The results from the $\left[2-{ }^{13} \mathrm{C}\right]$-glycine labelling and those from $\left[3-{ }^{13} \mathrm{C}\right]$-serine (see below) are consistent with a labelling pattern whereby the $\mathrm{C}-4$ position of each thiazole is labelled by [C-2]-glycine. This indicates that the original assignments for $\mathrm{C}-4$ and $\mathrm{C}-5$ of thiazole $\mathrm{D}$ were probably inverted, so that thiazole $\mathrm{D}$ represents an exception with respect to the other thiazole, in having the C-4 resonance at slightly lower fields than C-5 (see Table 1).]

A labelling experiment, performed adding $20 \mathrm{mg}$ of $\mathrm{L}-[3-$ $\left.{ }^{13} \mathrm{C}\right]$-serine after 24 and 48 hours of growth in the production medium, gave a total isotopic enrichment of about $25 \%$. The specific enrichments observed in this case are reported in Table 1. These signals have been ascribed to the $\mathrm{C}-5$ positions of the six thiazoles; to the $C$-methyl(ene) groups of thiazoles $\mathrm{D}$ and $\mathrm{E}$; to the $\mathrm{N}$ - and $O$-methyl groups; to the $\mathrm{C}-5$ carbon of the oxazoline; and to the $\mathrm{C}-4$ and $\mathrm{C}-5$ carbons of the pyridine ring. The results of the feeding experiments with Gly and Ser are summarized in Fig. 2. They indicate that the $\mathrm{C}-4$ position of all thiazoles is labelled by $\mathrm{C}-2$ of glycine, while the $\mathrm{C}-5$ position is labelled by C- 3 of serine. Thus, formation of GE2270 is very similar to that of other thiazolylpeptides: the thiazole rings are derived from serine, presumably after its conversion to cysteine; the pyridine ring is derived from the head to head condensation of two serine residues; and the oxazoline results from cyclization of serine.

These results were confirmed by a labelling experiment with $\left[\mathrm{U}-{ }^{13} \mathrm{C}\right]$-glycine, added under the same conditions as $\left[2-{ }^{13} \mathrm{C}\right]$-glycine. Satellite resonances, due to ${ }^{13} \mathrm{C}-{ }^{13} \mathrm{C}$ spinspin coupling, indicate incorporation of an intact glycine residue. This was observed, besides for the glycine residue itself, for the oxazoline, for all the thiazoles and for the pyridine ring (two units). Thus, a total ten intact glycine residues are incorporated into GE2270. These results, summarized in Fig. 2, are consistent with the enrichments from $\left[2-{ }^{13} \mathrm{C}\right]$-glycine and $\left[3-{ }^{13} \mathrm{C}\right]$-serine, and confirm the hypothesis that glycine is converted into serine, which in turn is the source of oxazoline rings and, presumably after its conversion into cysteine, of the thiazoles. The percentage enrichments after labeling with $\left[\mathrm{U}-{ }^{13} \mathrm{C}\right]$-glycine were also evaluated, considering the sum of the intensities of the central peak and of its satellites without any correction. Due to this fact and to the frequent overlapping of resonances, the ratio $r$ obtained for some positions of the $\left[U-{ }^{13} \mathrm{C}\right]$-glycine-fed GE2270 should be considered approximate. Most of the carbon atoms that were labelled either by $\left[2{ }^{13} \mathrm{C}\right]$-glycine or by $\left[3-{ }^{13} \mathrm{C}\right]$-serine were also enriched by $\left[\mathrm{U}-{ }^{13} \mathrm{C}\right]$-glycine. The only exceptions were the $\mathrm{C}-5$ positions of thiazoles $\mathrm{A}$ and $\mathrm{F}$ (Table 1). Furthermore, additional enrichments were observed at the $\mathrm{C}^{\prime}$ positions of thiazoles $\mathrm{D}, \mathrm{E}$ and $\mathrm{F}$, and of the oxazoline; at $\mathrm{C}-2$ of thiazoles A, B and F; and at $\mathrm{C}-2$ of the oxazoline. Thus, apart from the carbons of the Asn, Val, $(\beta$-OH)-Phe and Pro residues, most positions in GE2270 showed various degrees of enrichment.

It should be noted that the best enrichments for $\left[2-{ }^{13} \mathrm{C}\right]$ glycine were observed at positions corresponding to either $\mathrm{C}-2$ of the Gly residue, or to $\mathrm{C}-2$ of Ser-derived residues, indicating an efficient conversion of Gly into Ser. Furthermore, significant enrichments were also seen at positions equivalent to $\mathrm{C}-3$ of serine-derived residues, and to the $\mathrm{C}-, \mathrm{N}$ - and $O$-methyls, indicating that $\mathrm{C}-2$ of glycine can be an efficient source of methyl equivalents. Also [3${ }^{13} \mathrm{C}$-serine was an efficient source of methyl groups (Table 1). The enrichment observed for the two $C$-methyl groups was equivalent to that seen for the $N$ - and $O$ - methyls, indicating that all these methyls are derived from a cellular methyl donor. Thus, our results are consistent with thiazoles $\mathrm{D}$ and $\mathrm{E}$ being derived from cysteine, and subsequently being converted to the $C$-methylated forms. We tried also a labelling experiment with threonine. However, this amino acid severely repressed synthesis of GE2270. Consequently, we were unable to isolate enough labelled antibiotic for NMR analysis. Nonetheless, our results make it unlikely that the $C$-methylated thiazoles derive from incorporation of an $S$-analog of threonine. The observation that the methylene group of glycine is an effective source of methylating equivalents has been made during sulfomycin biosynthesis by Streptomyces arginensis ${ }^{12)}$, although in other studies of thiazolylpeptide formation by other actinomycete strains this phenomenon was not observed ${ }^{8)}$.

Addition of $\left[2-{ }^{13} \mathrm{C}\right]$-glycine resulted in enrichment of $\mathrm{C}-4$ and $\mathrm{C}-5$ of the oxazoline, as well as $\mathrm{C}-2$ through $\mathrm{C}-5$ of the pyridine ring. This result is consistent with the existence of a pathway whereby glycine is converted to serine by methylation, and $\mathrm{C}-2$ of glycine can generate methyl groups, as outlined below:

$$
\begin{gathered}
\mathrm{NH}_{2}{ }^{*} \mathrm{CH}_{2} \mathrm{COOH} \rightarrow \rightarrow\left[{ }^{*} \mathrm{CH}_{3}\right] \\
\mathrm{NH}_{2}{ }^{*} \mathrm{CH}_{2} \mathrm{COOH}+\left[{ }^{*} \mathrm{CH}_{3}\right] \rightarrow \rightarrow \mathrm{NH}_{2} * \underset{\mid}{ }{ }^{*} \mathrm{CHCOH} \\
{ }^{*} \mathrm{CH}_{2} \mathrm{OH}
\end{gathered}
$$

Judging from the similar enrichments seen for $\mathrm{C}-2$ of the Gly residue and for C- $\alpha$ of the oxazoline, it appears that the conversion of glycine into serine is quite efficient. On the other hand, the substantially higher enrichment seen at the oxazoline than at the thiazoles after feeding $\left[3-{ }^{13} \mathrm{C}\right]$-serine, 
Table 1. Incorporation ratios for the enrichment of GE2270 with ${ }^{13} \mathrm{C}$-labeled precursors.

\begin{tabular}{|c|c|c|c|c|c|}
\hline $\begin{array}{c}\text { Carbon } \\
\text { assignment }\end{array}$ & $\begin{array}{l}{ }^{13} \mathrm{C} \delta \\
(\mathrm{ppm})\end{array}$ & {$\left[2-{ }^{13} \mathrm{C}\right]$-Glycine } & $\begin{array}{c}\mathrm{DL}-\left[3-{ }^{13} \mathrm{C}\right]- \\
\text { Serine }\end{array}$ & $\begin{array}{l}{\left[1,2-{ }^{13} \mathrm{C}\right]-} \\
\text { Glycine }\end{array}$ & {$\left[2-{ }^{13} \mathrm{C}\right]$-acetate } \\
\hline $\mathrm{CH}_{3}$ Thiaz.E & 11.62 & 5.8 & 7.0 & 6.1 & \\
\hline $\mathrm{N}-\mathrm{CH}_{3} \mathrm{Asn}$ & 25.45 & 5.6 & 6.5 & 6.0 & \\
\hline$\beta$ Asn & 37.32 & & & & 3.6 \\
\hline$\alpha$ Gly & 40.89 & 8.9 & & 6.6 & \\
\hline$\alpha$ Asn & 47.84 & & & & 3.7 \\
\hline $\mathrm{CH}_{2}$ Thiaz.D & 58.25 & 6.2 & 7.8 & 6.1 & \\
\hline $\mathrm{OCH}_{3}$ Thiaz.D & 67.00 & 5.9 & 7.2 & 6.2 & \\
\hline C-4 Oxazoline & 67.77 & 9.5 & & 8.2 & \\
\hline C-5 Oxazoline & 69.05 & 4.7 & 9.5 & 5.7 & \\
\hline C-5 Thiaz.C & 116.0 & 1.7 & 3.7 & 1.5 & \\
\hline C-5 Pyridine & 118.2 & 5.6 & 9.9 & 3.2 & \\
\hline C-5 Thiaz.B & 122.7 & & 4.9 & 1.6 & \\
\hline C-5 Thiaz.F & 126.5 & & 4.2 & & \\
\hline C-3 Pyridine & 127.4 & 7.8 & & 5.9 & \\
\hline C-5 Thiaz.A & 128.3 & & 4.3 & & \\
\hline C-5 Thiaz.E & 139.1 & 1.5 & 3.2 & & \\
\hline C-4 Thiaz. $\mathrm{D}^{\mathrm{a}}$ & 140.7 & 2.6 & & 1.6 & \\
\hline C-4 Pyridine & 140.9 & 4.4 & 3.6 & 5.3 & \\
\hline C-4 Thiaz.E & 141.7 & 2.6 & & 2.9 & \\
\hline C-5 Thiaz. $\mathrm{D}^{\mathrm{a}}$ & 143.3 & 1.5 & 3.0 & 1.5 & \\
\hline C-4 Thiaz.A & 144.4 & 2.5 & & 2.2 & \\
\hline C-4 Thiaz.C & 146.5 & 2.8 & & 2.4 & \\
\hline C-4 Thiaz.F & 149.1 & 2.5 & & 2.7 & \\
\hline $\mathrm{C}-2$ or $\mathrm{C}-6 \mathrm{Pyr}$ & 150.0 & 7.9 & & 6.6 & \\
\hline C-4 Thiaz.B & 153.1 & 2.0 & & 2.0 & \\
\hline C-2 Oxazoline & 158.9 & & & 2.0 & \\
\hline C' Thiaz.F & 159.9 & & & 1.9 & \\
\hline C-2 Thiaz.B & 160.2 & & & 2.4 & \\
\hline $\mathrm{C}^{\prime}$ Thiaz.E & 160.8 & & & 2.5 & \\
\hline C-2 Thiaz.F & 164.4 & & & 6.5 & 1.7 \\
\hline C-2 Thiaz.D & 165.3 & & & & 1.4 \\
\hline C'-Oxazoline & 167.4 & & & 6.6 & 1.7 \\
\hline C-2 Thiaz.A & 167.9 & & & 5.8 & 1.7 \\
\hline C-2 Thiaz.E & 168.0 & & & & 2.4 \\
\hline C' Gly & 169.2 & 6.6 & & & 1.7 \\
\hline$\gamma$ Asn & 169.4 & 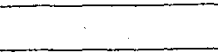 & & & 2.7 \\
\hline C'Pro & 173.3 & & & & 1.3 \\
\hline
\end{tabular}

ariginal assignments modified after this work.

suggests a substantial dilution of the label prior to incorporation into the thiazoles. It remains to be determined whether this apparent dilution is due to an excess of unlabelled precursor of the thiazoles (presumably cysteine) available for GE2270 formation, or to an inefficient conversion of serine into this precursor. The enrichments at $\mathrm{C}-5$ of thiazoles after feeding $\left[2-{ }^{13} \mathrm{C}\right]$-glycine are consistent with this label dilution: only three of the $\mathrm{C}-5$ positions of 
thiazole rings gave a significant enrichment, whereas for the other three the enrichment levels were very close to background, indicating a processive dilution as glycine is first converted into serine and the latter into cysteine. An alternative explanation for this observation might be due to the lower titers of GE2270 observed after addition of glycine (about $30 \%$ of control). Thus, the efficient conversion of glycine into serine might result from a repression or inhibition of serine utilization by glycine.

It is interesting to observe that, under our experimental conditions, the conversion of glycine to serine appears to be equivalent to the conversion of serine to cysteine, as judged from the similar enrichments observed at $\mathrm{C}-4$ of the oxazoline when feeding $\left[2-{ }^{13} \mathrm{C}\right]$-glycine, to that of $\mathrm{C}-5$ of thiazoles, when feeding $\left[3-{ }^{13} \mathrm{C}\right]$-serine. One anomaly that we observed in the pyridine enrichments is the higher level of enrichment observed at C-4 compared to that of C-5 after feeding $\left[3-{ }^{13} \mathrm{C}\right]$-serine. It has been proposed that the pyridine ring results from head to head condensation of two serine residues ${ }^{13)}$. The synthesis of the peptide chain in a thiazolylpeptide is believed to start from the pyridine ring, thereby the $\mathrm{C}-4$ position of pyridine would correspond to $\mathrm{C}-3$ of a putative starting (amino) acid. The lower enrichment at C-4 than at C-5 is consistent with the hypothesis that this putative initiator may not be serine itself, but one of its metabolites. It is worth mentioning that also MocEK et al. reported a similar discrepancy in the relative enrichments of the pyridine ring during their studies on the biosynthesis of thiostrepton ${ }^{10)}$.

The origin of the other residues in GE2270 has not been directly investigated. However, addition of $\left[2-{ }^{13} \mathrm{C}\right]$-acetate yielded some modest but significant enrichments (Table 1). The strongest enrichment was observed for all the carbons of the Asn residue and, to a lesser extent, for the C-2 positions of thiazole ring $\mathrm{E}$. Smaller but significant enrichments were also observed at the $\mathrm{C}-2$ positions of thiazoles $\mathrm{A}, \mathrm{D}$ and $\mathrm{F}$, as well as at the $\mathrm{C}$ ' positions of oxazoline and glycine (see Fig. 2). As expected by analogy with other thiazolylpeptides, acetate is poorly utilized as a carbon source during GE2270 formation under the experimental conditions employed. However, the labelling pattern observed for the asparagine residue is consistent with that expected after entry of acetate into the Krebs cycle and its conversion into oxaloacetate, which would then be transaminated to asparagine. The weak enrichment (but significantly above background) for the $\mathrm{C}-1$ position of glycine from $\mathrm{C}-2$ of acetate is consistent with similar enrichments seen at C-2 of at least some of the thiazoles. The subsequent conversion of glycine into serine by methylation would be consistent with the labelling of the C-
Fig. 2. Labeled positions in GE2270.

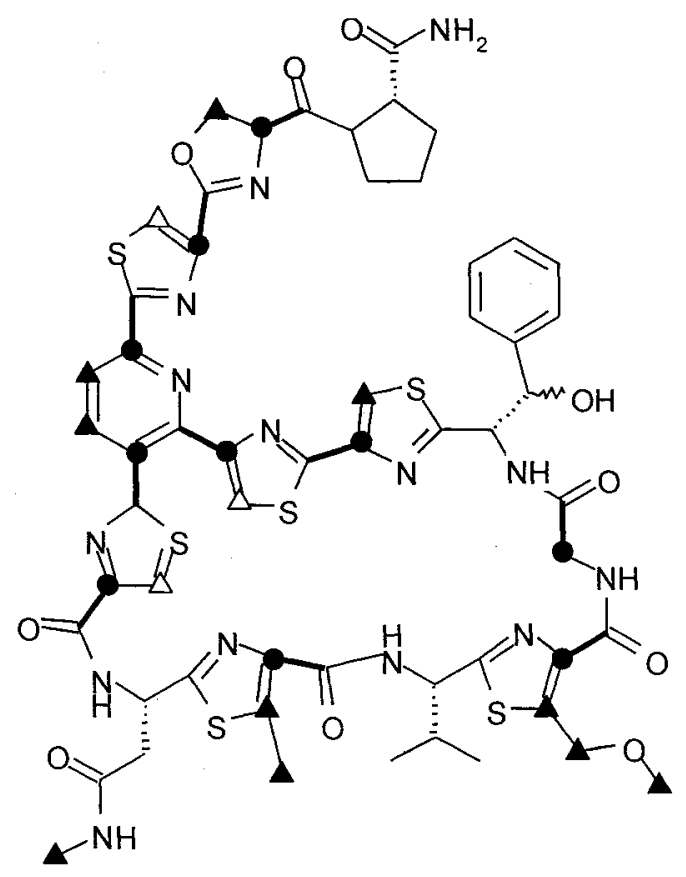

Positions labeled by $\left[2{ }^{13} \mathrm{C}\right]$-glycine are indicated by a dot; those labeled by $\left[2-{ }^{13} \mathrm{C}\right]$-glycine and $\left[3-{ }^{13} \mathrm{C}\right]-$ serine by a filled triangle; those labeled by $\left[3-{ }^{13} \mathrm{C}\right]-$ serine only by an empty triangle. Incorporation of an intact glycine residue is indicated by a thick line.

2 carbons of some thiazoles. Thus, our results suggest the existence of a pathway whereby acetate is converted into glycine in such a way that C-2 of acetate would become $\mathrm{C}-1$ but not $\mathrm{C}-2$ of glycine. We are unaware of reports describing such a conversion of acetate into glycine in actinomycetes.

In conclusion, our results show that the biosynthetic route to GE2270 can be considered very similar to that of better studied thiazolylpeptides such as nosiheptide and thiostrepton $^{9,10)}$. They also point to the existence in $P$. rosea of an active pathway for generating methylating equivalents from $\mathrm{C}-2$ of glycine. In addition, it appears that glycine is synthesized in this strain by a pathway involving the conversion of $\mathrm{C}-2$ of acetate into $\mathrm{C}-1$ of glycine.

Acknowledgements

We are grateful to our colleagues at Biosearch Italia for sharing information, methodologies and fruitful discussions. 


\section{References}

1) Selva, E.; G. Beretta, N. Montanini, G. S. Saddler, L. Gastaldo, P. Ferrari, R. Lorenzetti, P. Landini, F. Ripamonti, B. P. GoldsteIn \& M. Denaro: Antibiotic GE2270 A: a novel inhibitor of bacterial protein synthesis. I. Isolation and characterization. J. Antibiotics 44: $693 \sim 701,1991$

2) Shimanaka, $\mathrm{K}$;; $\mathrm{Y}$. Takahashi, $\mathrm{H}$. Innuma, $\mathrm{H}$. NAGANAWA \& T. TAKEUCHI: Novel antibiotics, amythiamycin. II. Structure elucidation of amythiamicin D. J. Antibiotics 47: 1145 1152, 1995

3) Stella, S.; N. Montanini, F. Le Monnier, P. Ferrari, L. Colombo, F. Marinelli, P. Landini, I. Ciciliato, B. P. Goldstein, E. SElva \& M. Denaro: Antibiotic GE37468 A: a new inhibitor of bacterial protein synthesis. I. Isolation and characterization. J. Antibiotics 48: 780 786, 1995

4) Anborgh, P. H. \& A. Parmeggíani: New antibiotics that act specifically on the GTP-bound form of elongation factor Tu. EMBO J. 10: 779 784, 1991

5) Landini, P.; M. Bandera, A. Soffientini \& B. P. GOLDSTEIN: Inhibition of bacterial protein synthesis by elongation-factor-Tu-binding antibiotics MDL 62,879 and efrotomycin. Biochem. J. 283: 649 652, 1992

6) Sosio, M.; G. Amati, C. Cappellano, E. Sarubbi, F. Monti \& S. DONADIO: An elongation factor Tu (EF-Tu) resistant to the EF-Tu inhibitor GE2270 in the producing organism Planobispora rosea. Mol. Microbiol. 22: 43 51, 1996

7) Thompson, J. E.; E. Cundliffe \& M. Stark: Binding of thiostrepton to a complex of 23-S RNA with ribosomal protein L11. Eur. J. Biochem. 98: 261 265, 1979

8) Favret, M. E.; J. W. Paschal, T. K. Elzey \& L. D. BOECK: Biosynthesis of thiopeptide antibiotic A10255: incorporation of isotopically-labeled precursors. J.
Antibiotics 45: 1499 1511, 1992

9) Mocek, U.; A. R. KNaggs, R. Tsuchiya, T. Nguyen, J. M. BEAlA \& H. Floss: Biosynthesis of the modified peptide antibiotic nosiheptide in Streptomyces actuosus. J. Am. Chem. Soc. 115: 7557 7568, 1993

10) Mocek, U.; Z. Zeng, D. O'Hagan, P. Zhou, L.-D. G. FAN, J. M. BeAle \& H. Floss: Biosynthesis of the modified peptide antibiotic thiostrepton in Streptomyces azureus and Streptomyces laurentii. J. Am. Chem. Soc. 115: 7992 8001, 1993

11) LAU, R. C. M. \& K. L. RINEHART: Biosynthesis of berninamycin: incorporation of ${ }^{13} \mathrm{C}$-labeled amino acids. J. Am. Chem. Soc. 117: 7606 7610, 1995

12) Fate, G. D.; C. P. Benner, S. H. Grode \& T. J. GILBERTSON: The biosynthesis of sulfomycin elucidated by isotopic labeling studies. J. Am. Chem. Soc. 118: 11363 11368, 1996

13) Roy, R. S.; A. M. Gehring, J. C. Milne, P. J. Belshaw \& C. T. WALSH: Thiazole and oxazole peptides: biosynthesis and molecular machinery. Nat. Prod. Rep. 16: 249 263, 1999

14) Goodfellow, M.: The family Streptosporangiaceae. In The Prokaryotes, 2nd edn. Ed., A. BALows et al., pp. 1115 1138, Springer-Verlag, 1992

15) Selva, E.; P. Ferrari, M. Kurz, P. Tavecchia, L. Colombo, S. Stella, E. Restelli, B. P. Goldstein, F. Ripamonti \& M. DEnARo: Components of the GE2270 complex produced by Planobispora rosea ATCC 53773. J. Antibiotics 48: 1039 1042, 1995

16) Colombo, L.; E. Selva \& S. Stella: Contribution of mass spectrometry to the structural confirmation of components of the antibiotic GE2270 complex. Rapid Commun Mass Spectrom 9: 717 722, 1995

17) Tavecchia, P;; P. Gentili, M. Kurz, C. Sottani, R. Bonfichi, S. Lociuro \& E. Selva: Revised structure of the antibiotic GE2270 A. J. Antibiotics 47: 1564 1567, 1994 